\title{
5-SULFOSALICYLIC ACID (5-SSA): AN EFFICIENT ORGANOCATALYST FOR THE SYNTHESIS OF 4-METHYLCOUMARINS VIA PECHMANN CONDENSATION
}

\author{
C. D. Bhenki ${ }^{1,2, *}$, S. S. Karhale ${ }^{1,3}$, K. N. Patil ${ }^{4}$ and V. B. Helavi ${ }^{1}$ \\ ${ }^{1}$ Department of Chemistry, Rajaram College, Kolhapur, (M.S.), India. \\ ${ }^{2}$ Department of Chemistry, Shri S. H. Kelkar College, Devgad, Sindhudurg,(M.S.), India. \\ ${ }^{3}$ Department of Chemistry, KarmaveerBhaurao Patil Mahavidyalaya (Autonomous), \\ Pandharpur,Solapur, (M.S.), India \\ ${ }^{4}$ Department of Chemistry, Dr.Ghali College, Gadhinglaj, (M.S.), India \\ "E-mail: cdbhenki@gmail.com
}

\begin{abstract}
An efficient synthetic route for the Pechmann condensation reaction of substituted phenols and $\beta$-ketoesters under solvent-free conditions using a Bronsted acid 5-sulfosalicylic acid (5-SSA) as an organocatalyst leading to the formation of coumarin derivatives is described. Using microwave heating, reaction times were reduced from $45 \mathrm{~min}$ to $6 \mathrm{~min}$. The attractive features of this protocol are mild reaction conditions, short reaction time, metal-free environment, easy workup procedure and improved synthesis which avoid chromatographic purification.

Keywords: Coumarin, Metal-free Environment, Microwave Irradiation, Organocatalyst, Green Chemistry etc.
\end{abstract}

(C) RASĀYAN. All rights reserved

\section{INTRODUCTION}

In the plant kingdom, an important group of naturally occurring compounds, coumarin moieties are widely distributed. Coumarins(benzo- $\alpha$-pyrone) are members of benzopyrone systems, which are found in many vegetables, seeds, fruits like bilberry, coffee, tea, nuts, cinnamon bark oil and wine. ${ }^{1,2}$ Synthetic coumarins are widely used as aroma chemicals because of their stability to alkali, odor strength and relatively cheap price. ${ }^{3}$ A coumarin as heterocyclic nucleus present in many natural products; therefore synthesis of coumarins has attracted considerable attention from the medicinal and organic chemist for many years. They occupy an important position, in synthetic organic chemistry,because of their potential applications in fragrance, pharmaceutical and agrochemical industries.

They are used as anticoagulants, cosmetics, additives in food, dispersed fluorescent laser dyes and optical brighteners and the preparation of insecticides. ${ }^{4-6}$ Many compounds containing the coumarin moiety possesses anti HIV and anticancer activity. ${ }^{7,8}$ In the synthesis of chromenes, furocoumarins, 2acylresorcinol and coumarones, coumarin also acts as intermediates. ${ }^{9}$ Thus the synthesis of heterocyclic nucleus, i.e.coumarins, is of much current interest. ${ }^{10,11}$ Wedelolactone and Novobiocin (Fig.-1)are naturally occurring products that are used as a venomous snake-bite antidoteand as an antibiotic respectively. ${ }^{12,13}$<smiles>O=c1oc2cc(O)cc(O)c2c2oc3cc(O)c(O)cc3c12</smiles><smiles>COC1OC2(Cc3ccc4c(O)c(NC(=O)c5ccc(O)c(CC=C(C)C)c5)c(=O)oc4c3)OCC1C(OC(N)=O)C2O</smiles>

Wedelolactone

Novobiocin

Fig.-1: Some Biologically Active Coumarin-based Compounds 
RASĀYAN J. Chem.

Vol. 13 | No. 4 |2466-2473| October - December | 2020

Pechmann,Reformatsky Knovengeal,Perkinand Wittig reactions are reported for the synthesis of coumarins. ${ }^{14-20}$ Pechmann reaction requires simple and inexpensive starting materials, i.e. phenols and $\beta$ ketoesters, and therefore the Pechmann reaction because of its simplicity,is a widely used method for synthesis of coumarin derivative, Conventionally, the Pechmann reaction is carried out in the presence of conc. $\mathrm{H}_{2} \mathrm{SO}_{4}$, phosphorus pentaoxide, aluminium chloride, trifluroacetic acid, ionic liquids, and PVPHWP,Zn[(L)-Proline $]_{2}$ as a catalyst. ${ }^{21-29}$ Long reaction time, tedious workup procedure, the requirement of special apparatus and use of organic solvents,all the above methods suffer from one or more disadvantages even these methods have their advantages. To reduce waste and costs, and to simplify the synthetic process and handling, the reactions are carried out under solvent-free condition. ${ }^{30}$ Development of organic synthesis in which the reactions are catalyzed by organocatalyst is an important area for the green procedure.$^{31}$ However to the best of our knowledge, the organocatalyzed synthesis of coumarins has not been accomplished. Thus in the view of the importance of coumarin compounds, the development of an efficient, simple and versatile method for the preparation of coumarins by Pechmann condensation is an active research area and there is a scope for further improvement in the reaction condition and product yields. In continuation of our research work in the development of the green procedure, for the synthesis of biologically active moieties, we have developed an organocatalytic synthesis of coumarin derivatives. ${ }^{32-35}$

Three-component Mannich reactions, as well as synthesis of 1-amido alkyl 2-naphthol and 3,4disubstituted isooxazol-5(4H)-ones using 5-sulfosalicylic acid catalyst,was reported. ${ }^{36,37}$ This work was attractive for us to test the feasibility of 5-SSA as a novel basic organocatalyst in the synthesis of Coumarin derivatives. The metal-free organocatalytic process can reduce the cost and avoid the pollution caused by metals therefore, metal-free catalysts are regarded as green catalysts. Microwave provides a powerful way to do synthetic chemistry in the green approach. Material may be heated, in a microwave oven with the use of high-frequency electromagnetic waves. Due to the interaction of the electric field component of the wave with the charged particle in the material, heating arises. The heat is generated through resistance to an electric current, through the conduction mechanism. An oscillation of electrons or ions in a conductoris generated due to the oscillating electromagnetic field, which results in an electric current.The electric current generated faces internal resistance, which then heats the conductor.Microwave irradiation was preferred for heating the reaction mixtures because utilization of microwaves generally reduces reaction time and improves yields. ${ }^{38}$ In this study, we have developed the synthesis of coumarins by Pechmann condensation of substituted phenols and ethyl acetoacetate using 5SSA as a mild and efficient organocatalyst under solvent-free conditions using conventional heating as well as microwave irradiation.

\section{EXPERIMENTAL}

\section{Materials and Methods}

5-sulfosalicylic acid (Spectrochem), substituted phenols (Spectrochem and Thomas Baker), and ethyl acetoacetate (Thomas Baker) were used as received.An open atmosphere and dried glassware are used to carry out all reactions.A hot paraffin bath is used for recording the melting points of all synthesized compounds and is uncorrected. Synthesis of coumarin derivatives was carried out under solvent-free conditions using the Microwave Synthesizer System (Milestone Srl, Sorisol (BG), Italy). The IR spectra were recorded on Alpha100508,FT-IR spectrometer in the frequency range 500-4000 $\mathrm{cm}^{-1}$. The NMR spectra were recorded on a Bruker Avance (400 MHz for ${ }^{1} \mathrm{H}$ NMR and $100 \mathrm{MHz}$ for ${ }^{13} \mathrm{C}$ NMR) spectrometer using DMSO as solvent using Tetramethylsilane (TMS) as an internal standard. Chemical shifts $(\delta)$ are expressed in parts per million (ppm).

\section{Thermal Heating}

A mixture of resorcinol $(1 \mathrm{mmol})$, ethyl acetoacetate $(1 \mathrm{mmol})$ and $20 \mathrm{~mol} \%$ 5-SSA was mixed and magnetically stirred at $80^{\circ} \mathrm{C}$ for time intervals $(20-45 \mathrm{~min}$.). The completion of the reaction was confirmed by TLC (n-hexane: ethyl acetate, $3: 1$ ) and then ice-cold water was poured into the reaction mixture.A pure solid was obtained by scratching the beaker,which was filtered, dried and recrystallized from ethanol to obtain coumarins in good yield and high purity. The 5-SSA is water-soluble which is recovered by evaporating water from the filtrate under vacuum, dried, and then used for the next cycle. 
RASĀYAN J. Chem.

Vol. 13 | No. 4 |2466-2473| October - December | 2020

\section{Microwave Irradiation}

A mixture of resorcinol $(1 \mathrm{mmol})$, ethyl acetoacetate $(1 \mathrm{mmol})$ and $20 \mathrm{~mol} \%$ 5-SSA catalyst was irradiated in a microwave synthesizer system at $320 \mathrm{~W}$ for $6 \mathrm{~min}$. Work-up was done as reported in the thermal method.

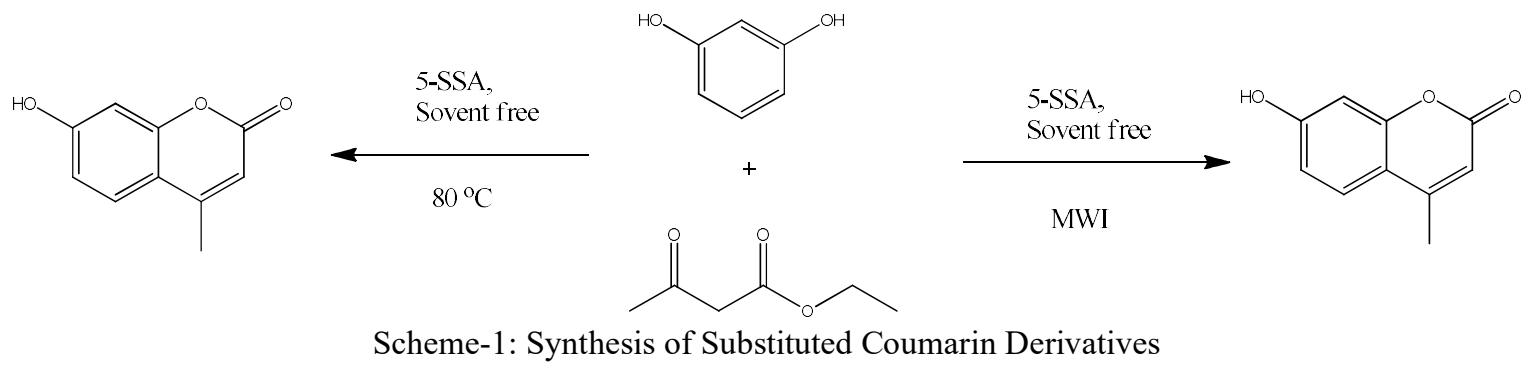

\section{Spectral Data of Representative Compound}

7-hydroxy-4-methylcoumarin (Table-4, 3a)

FT-IR $(\mathrm{KBr})\left(\mathrm{cm}^{-1}\right): \mathrm{v}=3299,3050,2850,1695$; ${ }^{1} \mathrm{H}$ NMR (400 MHz, $\left.\mathrm{CDCl}_{3}\right): \delta 10.25$ (br.s, $\left.1 \mathrm{H}, \mathrm{OH}\right)$, 7.43-7.41 $(J=8.8 \mathrm{~Hz}), \delta 6.64-6.65(\mathrm{~J}=8.8 \mathrm{~Hz})(\mathrm{d}, 3 \mathrm{H}), 6.71-6.74(\mathrm{~m}, 3 \mathrm{H}), 5.97(\mathrm{~s}, 1 \mathrm{H}), 2.32(\mathrm{~s}, 3 \mathrm{H}) . ;{ }^{13} \mathrm{C}$ NMR $\left(100 \mathrm{MHz}, \mathrm{CDCl}_{3}\right): \delta 18.6,102.7,110.6,112.4,113.2,126.0,153.2,155.2,161.4 . ; \mathrm{MS}(\mathrm{EI}): \mathrm{m} / \mathrm{z}$ $176[\mathrm{M}]^{+}$.

\section{7,8-Benzo-4-methylcoumarin. (Table-4,3b)}

FT-IR (v in $\left.\mathrm{cm}^{-1}\right): 1590,1566,1474,1630 .{ }^{1} \mathrm{H}$ NMR $\left(400 \mathrm{MHz}, \mathrm{CDCl}_{3}\right): \delta 8.5(\mathrm{~d}, 1 \mathrm{H}, \quad), 7.8(\mathrm{~d}, 1 \mathrm{H}$,$) ,$ 7.5-7.6(m, 2H, ), $7.4(\mathrm{~d}, 1 \mathrm{H}),, 6.9(\mathrm{~d}, 1 \mathrm{H}),, 6.4(\mathrm{~s}, 1 \mathrm{H}), 2.5(\mathrm{~s}, 3 \mathrm{H})$.

\section{6,7-Benzo-4-methylcoumarin. (Table-4,3c)}

IR (v in cm $\left.{ }^{-1}\right): 1601,1512,1464,1630 . ;{ }^{1} \mathrm{H}$ NMR(400 MHz, $\left.\mathrm{CDCl}_{3}\right): \delta 7.7(\mathrm{~s}, 2 \mathrm{H}), 7.6(\mathrm{~d}, 1 \mathrm{H}), 7.2-$ 7.4(m, 2H), $7.1(\mathrm{~d}, 1 \mathrm{H}), 5.2(\mathrm{~s}, 1 \mathrm{H}),, 1.7(\mathrm{~s}, 3 \mathrm{H})$.

\section{8-Nitro-4-methylcoumarin. (Table-4,3d)}

IR ( $v$ in $\left.\mathrm{cm}^{-1}\right)$ : 1510, 1450(aromatic ring), $1600(\mathrm{C}=\mathrm{O}), 1591,1335(\mathrm{NO} 2), 1295,1195(\mathrm{C}-\mathrm{O}) \cdot ;{ }^{1} \mathrm{H}$ $\operatorname{NMR}\left(400 \mathrm{MHz}, \mathrm{CDCl}_{3}\right): \delta 7.8(\mathrm{~d}, 1 \mathrm{H}),, 7.1(\mathrm{~d}$ of d, $1 \mathrm{H}), 6.9(\mathrm{~d}, 1 \mathrm{H}), 3.3(\mathrm{~s}, 1 \mathrm{H}), 2.5(\mathrm{~s}, 3 \mathrm{H})$.

\section{RESULTS AND DISCUSSION}

An efficient protocol for the synthesis of coumarin using 5-SSA as catalyst under solvent-free conditions is reported. The structure of 5-Sulfosalicylic acid is given below:

\section{Optimization of Reaction Conditions}<smiles>O=C(O)c1cc(S(=O)(=O)O)ccc1O</smiles>

For the optimization of reaction condition, we investigated our study by choosing resorcinol and ethylacetoacetate (EAA) as a model substrate by using various mmols of catalyst and MW power levels for 4 to $6 \mathrm{~min}$. When there is no catalyst, we got the low yield of the desired product which indicates the vital role of the catalyst.

$20 \mathrm{~mol} \%$ of 5 - SSA catalyzes the reaction smoothly and optimized trials were summarized in Table-1. The reaction continuity was checked by taking TLC (Ethyl acetate/ n-hexane, 2:1 as a solvent system) at various time intervals. We observed that higher catalyst amount, $25 \mathrm{~mol} \%$ and $320 \mathrm{~W}, 40 \%$, MWI power yielded desired product 7-hydroxy-4-methylcoumarin in a short time 4 min with $90 \%$ yield but more suitable reaction condition to obtain the desired product in acceptable yield, $90 \%$ was using $20 \mathrm{~mol} \%$ of 5-SSA as a catalyst and $320 \mathrm{~W}, 40 \%$ MWI for 6 min (Table-1).

The efficiency of 5-SSA was also checked by the conventional heating method and same model reaction conditions with variable temperature and time and the results were given in Table-2. It was observed that in conventional heating satisfactory results for the synthesis of 7-hydroxy-4-methyl coumarin were 
RASĀYAN J. Chem.

Vol. 13 | No. 4 |2466-2473| October - December | 2020

obtained at $80^{\circ} \mathrm{C}$ for 20 min with $85 \%$ yield (Table-2, entry 5). The yield obtained for model reaction in MWI (yield 90\%) is higher than conventional heating and reaction time reduced from 20 min to 6 min.

\begin{tabular}{|c|c|c|c|c|c|}
\hline $\begin{array}{l}\text { mol\% of } 5- \\
\text { SSA and } \\
\text { Microwave } \\
\text { Power }\end{array}$ & Time (s) & TLC & $\begin{array}{c}\text { mol\% of 5- SSA } \\
\text { and Microwave } \\
\text { Power }\end{array}$ & Time (s) & TLC \\
\hline \multirow{4}{*}{$\begin{array}{c}0 \\
240 \mathrm{~W} \\
(30 \%) \\
\end{array}$} & 120 & NP & \multirow{4}{*}{$\begin{array}{c}0 \\
320 \mathrm{~W}(40 \%)\end{array}$} & 120 & NP \\
\hline & 240 & NP & & 240 & NP \\
\hline & 360 & $\mathrm{NP}$ & & 360 & NP \\
\hline & 480 & NP & & 480 & $\mathrm{TP}$ \\
\hline \multirow{4}{*}{$\begin{array}{c}10 \\
240 \mathrm{~W} \\
(30 \%) \\
\end{array}$} & 120 & NP & \multirow{4}{*}{$\begin{array}{c}10 \\
320 \mathrm{~W}(40 \%)\end{array}$} & 120 & $\mathrm{TP}$ \\
\hline & 240 & NP & & 240 & $\mathrm{TP}$ \\
\hline & 360 & $\mathrm{TP}$ & & 360 & CRM \\
\hline & 480 & $\mathrm{TP}$ & & 480 & CRM \\
\hline \multirow{4}{*}{$\begin{array}{c}20 \\
240 \mathrm{~W} \\
(30 \%) \\
\end{array}$} & 120 & NP & \multirow{4}{*}{$\begin{array}{c}20 \\
320 \mathrm{~W}(40 \%)\end{array}$} & 120 & CRM \\
\hline & 240 & $\mathrm{TP}$ & & 240 & $\mathrm{P}+\mathrm{CRM}$ \\
\hline & 360 & $\mathrm{TP}$ & & 360 & $\mathrm{P}+\mathrm{MRI}(90 \%)$ \\
\hline & 480 & CRM & & 480 & $\mathrm{P}+\mathrm{MRI}$ \\
\hline \multirow{4}{*}{$\begin{array}{c}25 \\
240 \mathrm{~W} \\
(30 \%) \\
\end{array}$} & 120 & $\mathrm{TP}$ & \multirow{4}{*}{$\begin{array}{c}25 \\
320 \mathrm{~W}(40 \%)\end{array}$} & 120 & CRM \\
\hline & 240 & $\mathrm{TP}$ & & 240 & P+MRI(90\%) \\
\hline & 360 & CRM & & 360 & $\mathrm{P}+\mathrm{MRI}$ \\
\hline & 480 & CRM & & 480 & $\mathrm{P}+\mathrm{MRI}$ \\
\hline
\end{tabular}

TP: Trace Product NP: No Product, CRM: Complex Reaction Mixture, P: Product, MRI: Minor Reaction Impurities

Table-2: Conventional Heating Methods to Optimize the Reaction Conditions

\begin{tabular}{|c|c|c|c|}
\hline Entry & $\begin{array}{c}\text { Temperature ( } \\
\left.0^{0} \mathrm{C}\right)\end{array}$ & Time $(\min )$ & Yield $^{\mathrm{b}}(\%)$ \\
\hline 1 & $\mathrm{RT}$ & 90 & 48 \\
\hline 2 & 45 & 60 & 52 \\
\hline 3 & 60 & 45 & 65 \\
\hline 4 & 70 & 45 & 70 \\
\hline 5 & 80 & 20 & 85 \\
\hline
\end{tabular}

${ }^{\mathrm{a}}$ Reaction conditions: Resorcinol $(1 \mathrm{mmol})$, Ethylacetoacetate $(1 \mathrm{mmol})$, and 5-SSA $(20 \mathrm{~mol} \%)$ at a given temperature, ${ }^{\mathrm{b}}$ Isolated yield

From an enviro-economic point of view, the reusability of the catalyst was highly significant so the study was carried out using resorcinol $(1 \mathrm{mmol})$, ethyl acetoacetate $(1 \mathrm{mmol})$ and $20 \mathrm{~mol} \%, 5$-SSA catalyst as model substrates. Subsequently, 5-SSA is water-soluble which is recovered by evaporating water from the filtrate under vacuum, dried, and then used for the next cycle. The reusability of 5-SSA was studied efficiently by using the same model substrates under optimized reaction conditions. Recyclability of the 5-SSA catalyst was checked to four consecutive cycles having yield $90-80 \%$ (Fig.-2). The reusability of 5-SSA was examined efficiently using Resorcinol as a model substrate. The recovered 5-SSA was reused directly for three consecutive cycles, and all the results are summarized in Table-3. After the third cycle $85 \%$ of the catalyst is recovered, and it gives $80 \%$ of the coumarin product. 
RASĀYAN J. Chem.

Vol. 13 | No. 4 |2466-2473| October - December | 2020

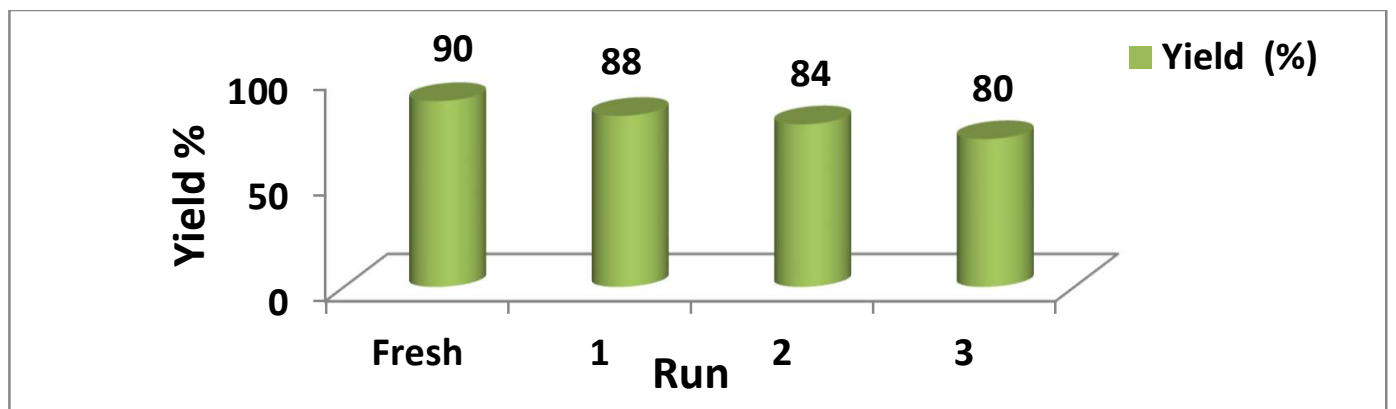

Fig.-2: Recyclability of the 5-SSA Catalyst

Table-3: Catalyst Recovery for the Synthesis of Coumarin Derivatives ${ }^{\text {a }}$

\begin{tabular}{c|c|c|c}
\hline Entry & Number of Cycles & Catalyst Recovery & ${\text { Yield }(\%)^{\mathrm{b}}}^{\text {Y }}$ \\
\hline 1 & Cycle 1 & 98 & 90 \\
\hline 2 & Cycle 2 & 94 & 88 \\
\hline 3 & Cycle 3 & 90 & 84 \\
\hline 4 & Cycle 4 & 85 & 80 \\
\hline
\end{tabular}

${ }^{\text {a}}$ ReactionConditions: resorcinol $(1 \mathrm{mmol})$, ethylacetoacetate $(1 \mathrm{mmol})$, and 5-SSA(20 $\left.\mathrm{mol} \%\right)$ at a given temperature, ${ }^{\mathrm{b}}$ Isolated yield

To further establish the scope of optimized reaction conditions and to generalize the synthetic procedure, a variety of substituted phenols were treated with ethylacetoacetate under conventional and microwave irradiation method. The presence of electron-donating and electron withdrawing groups on the aromatic rings does not affect the yield of the product. All the results are compiled in Table- 4 .

Table-4: Comparison between Classical and Microwave Heating for the Synthesis of Coumarin Derivatives $^{\text {a }}$

\begin{tabular}{|c|c|c|c|c|c|c|c|}
\hline & $1(a-i$ & . & & & $3(a-i)$ & & \\
\hline \multirow[t]{2}{*}{ Entries } & \multirow{2}{*}{$\begin{array}{c}\text { Aryl } \\
\text { Aldehyde }\end{array}$} & \multirow[t]{2}{*}{ Product } & \multirow{2}{*}{$\begin{array}{c}\text { M.P. }{ }^{\circ} \mathrm{C} \\
\text { (References) }\end{array}$} & \multicolumn{2}{|c|}{ Classical Heating } & \multicolumn{2}{|c|}{ Microwave Heating } \\
\hline & & & & Time/min & Yield $^{\mathrm{b}}(\%)$ & Time $/ \mathrm{min}$ & Yield $^{\mathrm{b}}(\%)$ \\
\hline 1 & Resorcinol & $3 \mathrm{a}$ & $\begin{array}{c}183-185 \\
{[38]}\end{array}$ & 20 & 85 & 6 & 90 \\
\hline 2 & $\alpha$-Naphthol & $3 \mathrm{~b}$ & $\begin{array}{c}152-154 \\
{[38]}\end{array}$ & 30 & 78 & 7 & 82 \\
\hline 3 & $\beta$-Naphthol & $3 c$ & $\begin{array}{c}187-189 \\
\text { [39] }\end{array}$ & 30 & 72 & 8 & 75 \\
\hline
\end{tabular}


RASĀYAN J. Chem.

Vol. 13 | No. 4 |2466-2473| October - December | 2020

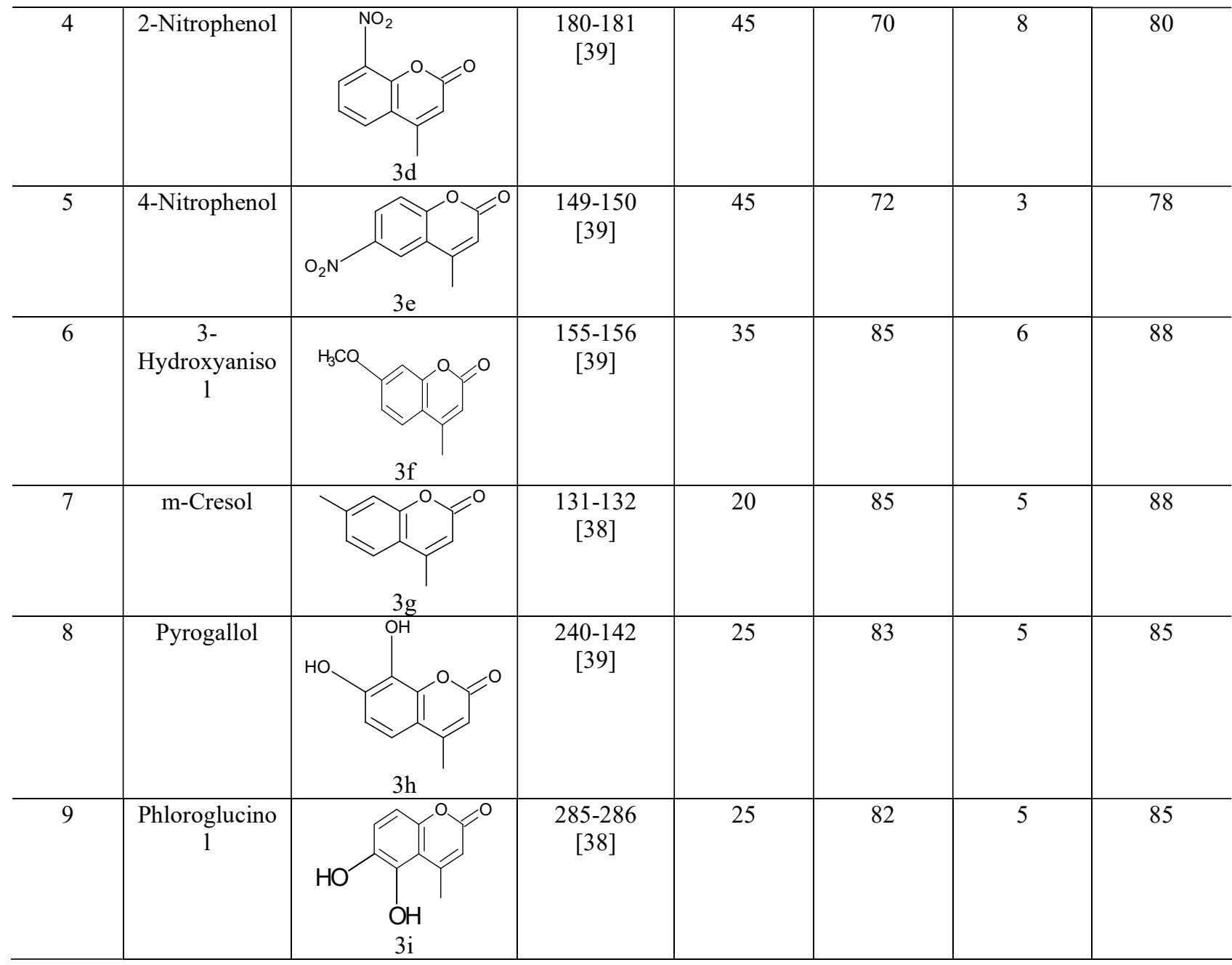

${ }^{\mathrm{a}}$ ReactionConditions: substituted phenols (1mmol), EAA (1 mmol), and 5-SSA(20 mol\%) under solvent-free condition, ${ }^{\mathrm{b}}$ Isolated yield of purified products.

Table-5: Comparison with a Variety of Catalysts for the Reaction of Resorcinol with EAA

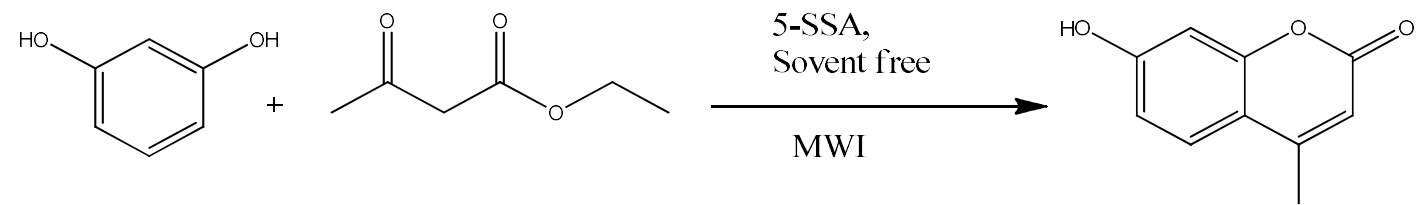

\begin{tabular}{c|c|c|c|c|c|c}
\hline $\begin{array}{c}\text { S. } \\
\text { No. }\end{array}$ & Catalyst & $\begin{array}{c}\text { Amount of Catalyst } \\
(\mathrm{mol} \%)\end{array}$ & Temp. $\left({ }^{\circ} \mathrm{C}\right)$ & Time & $\begin{array}{c}\text { Yield } \\
(\%)\end{array}$ & Ref. \\
\hline 1 & $5-\mathrm{SSA}$ & 10 & $\mathrm{MW}$ & $6 \mathrm{~min}$ & 90 & This Work \\
\hline 2 & $\mathrm{SnCl}_{2} .2 \mathrm{H}_{2} \mathrm{O}$ & 10 & 80 & $150 \mathrm{~min}$ & 52 & {$[42]$} \\
\hline 3 & Silica nano composite & 20 & Reflux & $2 \mathrm{~h}$ & 81 & {$[22]$} \\
\hline 4 & Amberlyst & 20 & Reflux & $2 \mathrm{~h}$ & 95 & {$[43]$} \\
\hline 5 & Conc. $\mathrm{H}_{2} \mathrm{SO}_{4}$ & 20 & 10 & $12 \mathrm{~h}$ & 50 & {$[40]$} \\
\hline 6 & Mont.K10 & 20 & 150 & $6 \mathrm{~h}$ & 70 & {$[41]$} \\
\hline 7 & Al-MCM & 20 & 150 & $6 \mathrm{~h}$ & 70 & {$[44]$} \\
\hline 8 & IL & 20 & 85 & $2 \mathrm{~h}$ & 75 & {$[13]$} \\
\hline
\end{tabular}

The comparison of 5-SSA with the other reported catalyst employed for the reaction of resorcinol with EAA is shown in Table-5. This result reveals that 5-SSA is a highly efficient catalyst under microwave conditions in terms of reaction time and yield for the synthesis of Coumarin Derivatives. 
RASĀYAN J. Chem.

Vol. 13 | No. 4 |2466-2473| October - December | 2020

The plausible mechanism for the 5-SSA catalyzed synthesis of 7-hydroxy-4-methylcoumarin under solvent-free conditions is shown in Scheme-2. In this mechanism, 5-SSA activates EAA by protonation, making the carbonyl group susceptible to nucleophilic attack by resorcinol.7-hydroxy-4-methylcoumarin was produced and the catalyst was regenerated simultaneously through the transesterification and dehydration reaction.
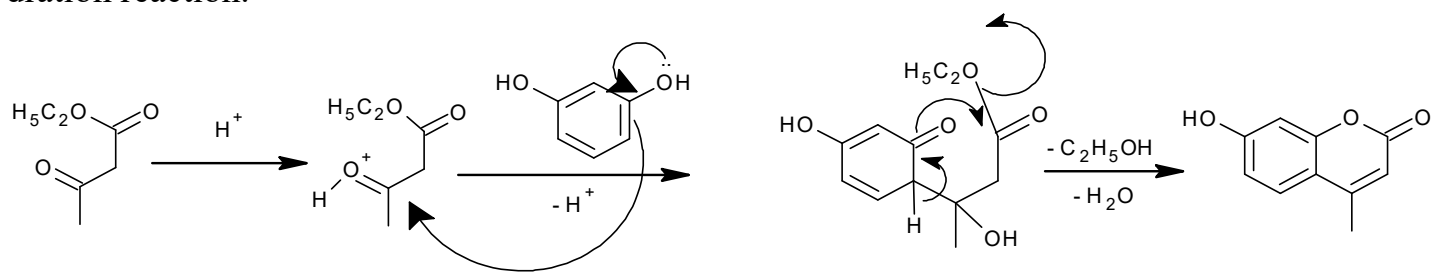

Scheme-2: The Plausible Mechanism for the Synthesis of 7-hydroxy-4-methylcoumarin

\section{CONCLUSION}

In summary, we have carried out the optimization of Pechmann reaction of resorcinol with ethyl acetoacetate by using 5-SSA as catalysts under solvent-free conditions using microwave irradiation for the synthesis of 7-hydroxy-4-methylcoumarin.All products obtained by the condensation reaction of substituted phenols with ethyl acetoacetate (EEA) under solvent-free conditions using microwave irradiation, gave good to excellent yields. The present method has several advantages such as short time, metal-free synthesis, high reaction rates, excellent yields, no side reaction, cost efficiency, ease of handling of the catalyst, and a simple experimental procedure.

\section{ACKNOWLEDGEMENT}

CDB is thankful to Management Shikshan Vikas Mandal,Principal of Shri S. H. Kelkar College of Art's, Commerce and Science,Devgad, Dist. Sindhudurg, for encouragement,Department of Chemistry, Solapur University, Solapur for providing spectral data and the University of Mumbai, Mumbai for Financial Assistance under Minor Research Project Scheme.

\section{REFERENCES}

1. A.Lacy,and R. O'Kennedy, Current Pharmaceutical Design, 10, 3797(2004), DOI: $10.2174 / 1381612043382693$

2. E. Kouloura, E. Danika,E. Kim, S. Hoerle, M. Cuendet, M. Halabalaki, and M Skaltsounis, Molecules, 19, 15042 (2014), DOI:10.3390/molecules190915042

3. R. S. Keri, B. S. Sasidhar, B. M. Nagaraja and M. A. Santos, Europian Journal of Medicinal Chemistry, 100, 257(2015), DOI:10.1016/j.ejmech.2015.06.017

4. R. O'Kennedy, R. D. Thornes, Coumarins: Biology, Applications, and Mode of Action; Wiley \& Sons: Chichester, (1997).

5. R. D. H. Murray, J. Mendez and S. A. Brown, The Natural coumarins: Occurrence, Chemistry and Biochemistry, Willey: New York, (1992).

6. M. Zahradnik, The Production and Application of Fluorescent Brightening Agents, Wiley,New York. (1992).

7. I. Kostova, S. Raleva, P. Genova, and R. Argirova, Bioinorganic Chemistry and Appllications, 1,(2006), DOI:10.1155/BCA/2006/68274

8. C. J. Wang, Y.J. Hsieh, C.Y. Chu, Y.L. Lin, and T.H Tseva, Cancer Letter, 183, 163 (2002), DOI: $10.1016 / \mathrm{S} 0304-3835(02) 00031-9$

9. S. M. Sethna, and N. P. Kong, Chemical Reviews, 36, 1 (1945), DOI:10.1021/cr60113a001

10. Kumar, S. Tomas, R. Patel, A. Yousaf, V. Parmarand, S. Malhotra, Synthetic Communications, 38, 2646(2008), DOI: 10.1080/00397910802219569

11. R. Kerr, K. Hosamani, H. Seetharama Reddy, Catalysis. Letters,131,321(2009), DOI: $10.1007 / \mathrm{s} 10562-009-9940-\mathrm{Z}$

12. J. Wu, Y. Lia and Z. Yang, Journal of Organic Chemistry, 66, 3642(2001), DOI:10.1021/jo0102157

13. S. Das, A. Majee and A. Hajara, Green Chemistry Letters and Reviews, 4, 349(2011), DOI: $10.1080 / 17518253.2011 .572296$ 
RASĀYAN J. Chem.

Vol. 13 | No. 4 |2466-2473| October - December | 2020

14. V. Pechmann and C. Duisberg, Chemische Berichte,17,929(1884), DOI:10.1039/JS8682100053

15. Shriner,L.Ralph Organic Reactions, 1,1(1942), DOI:10.1002/0471264180.or001.01

16. G. Jones, Organic Reactions, 15, 204(1967), DOI:10.1002/0471264180.or015.02

17. G. Brufola, F. Frinueli, O. Piermatti and F. Pizzo, Heterocycles, 43, 1257(1996).

18. J.R Jonson, Organic Reactions, 210, 1(1942).

19. N.S. Narsiman, R.S. Mali and M. V. Barve, Synthesis, 906 (1979).

20. I. Yavari, H. Shoar, A. Zonouzi, Tetrahedron Letters, 39, 2391(1998), DOI:10.1016/S00404039(98)00206-8

21. A. Russel, J.R. Frye, Organic, Syntheses, 21, 22(1941).

22. M. C. Laufer, H. Hausmann and W.F. Hoderich, Journal of Cataysis, 218, 315(2003), DOI: $10.1016 / \mathrm{S} 0021-9517(03) 00073-3$

23. A. Robertson,W.F. Sandrock and C.B. Hendry, Journal of the Chemical Society, 5, 2426(1931), DOI: $10.1039 / J R 9310002426$

24. B. Tyagi, M.K. Mishra, and R.V. Jasra, Journal of Molecular Catalysis A: Chemical, 276, 47(2007), DOI: $10.1016 /$ j.molcata.2007.06.003

25. L.L. Woods, Journal of Organic Chemistry, 27, 3703(1962), DOI:10.1021/jo01057a519

26. M. K. Potdar, S. S. Mohile and M. M. Salunkhe, Tetrahedron Letters, 42, 9285(2001), DOI: 10.1016/S0040-4039(01)02041-X

27. N. G. Khaligh, Catalysis Science and Technology, 2,16339(2012), DOI:10.1039/C2CY20196H

28. S. Li, X. Qi and B. Huang, Catalysis Today, 276,139(2016), DOI:10.1016/jcattod.2015.12.022

29. O. S. Chavan, S. A. Jadhav, M. G. Shioorkar,S. B. Chavan,M. A. Baseer, D. B. Shinde, Rasyan Jounal of Chemistry, 8,194(2015)

30. Solvent Free Organic Synthesis, ed, K. Tanaka, $2^{\text {nd }} e d n$. Wiley-VCH, Weinhein, (2008).

31. A. Khaskel, P.Gogoi, P. Barman and B. Bandyopadhyay,Royal Society of Chemistry Advances, 4, 3559(2014), DOI: 10.1039/C4RA16627B

32. S. Karhale, K. Patil, C. Bhenki, G. Rashinkar, V. Helavi, Research on Chemical Intermediate, 42, 7257(2016), DOI:10.1007/s11164-016-2534-7

33. S. Karhale, D. Survase, R. Bhat, P. Ubale and V. Helavi, Research on Chemical Intermediate, 43, 3915(2017), DOI: 10.1007/s11164-016-2855-6

34. C. Bhenki, S. Karhale and V. Helavi, Iranian Journal of Catalysis, 6, 409(2016).

35. S. Karhale, C. Bhenki, G. Rashinkar and V. Helavi, New Journal of Chemistry, 41, 5133(2017), DOI: 10.1039/C7NJ00685C

36. C. Chen, X. Zhu, Y. Wu, H. Sun, G. Zhang,W. Zhang, Z. Gao,Journal of Molecular Catalysis A: Chemical, 395,124(2014), DOI: 10.1016/j.molcata.2014.08.017

37. H. Kiyani, H. Darbandi, A. Mosallanezhad, F. Ghorban, Research on Chemical Intermediate ,41, 7561 (2015), DOI: 10.1007/s11164-014-1844-X

38. V. Singh, J. Singh, K.P. Kaur and G.L. Kad, Journal of Chemical Research, (S), 58(1997), DOI: $10.1039 / \mathrm{A} 605672 \mathrm{E}$

39. F. Shirini, N. G. Khaligh, Chinese Journal of Catalysis, 34, 1890(2013), DOI:10.1016/S18722067(12)60669-X

40. B. Sandhya ,V. Mathew, P. Lohitha, Ashwini T. A. Shravani, International Journal of Chemical and Pharmaceutical Sciences, 1, 16(2010).

41. H. Kolancilar, Asian Journal of Chemistry, 22, 5685(2010).

42. K. K. Upadhyay, R. K. Mishra, A. Kumar, Catalysi Letteters, 121, 118 (2008), DOI: 10.1007/s10562-007-9307-2

43. R. Sabou, W.F. Hoelderich, D. Ramprasad, R. Weinand, Journal of Catalysis, 232, 34(2005), DOI: 10.1016/j.jcat.2005.02.002

44. S. Sudha, K. Venkatachalam, S. Vishnu Priya, J. Herbert Mabel, M. Palanichamy, V. Murugesan, Journal of Molecular Catalysis A: Chemical, 291, 22(2008), DOI:10.1016/j.molcata.2008.04.021

[RJC-5950/2020] 